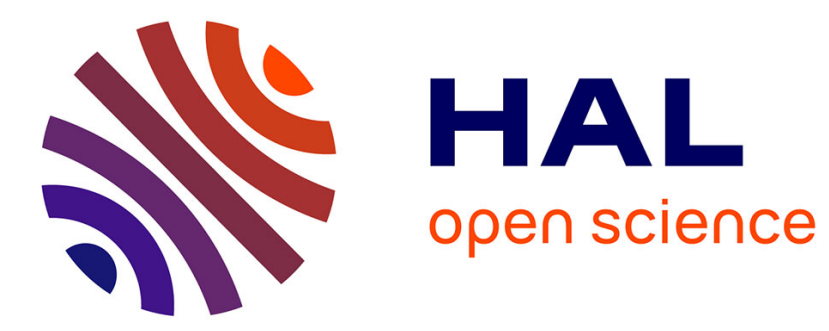

\title{
LGMD: Optimal Lightweight Metadata Model for Indexing Learning Games
}

\author{
Maho Wielfrid Morie, Iza Marfisi-Schottman, Bi Tra Goore
}

\section{To cite this version:}

Maho Wielfrid Morie, Iza Marfisi-Schottman, Bi Tra Goore. LGMD: Optimal Lightweight Metadata Model for Indexing Learning Games. International Conference on Smart Applications and Data Analysis for Smart Cyber-Physical Systems (SADASC), Mar 2020, Marrakech, Morocco. hal-02484579

\section{HAL Id: hal-02484579 \\ https://hal.science/hal-02484579}

Submitted on 19 Feb 2020

HAL is a multi-disciplinary open access archive for the deposit and dissemination of scientific research documents, whether they are published or not. The documents may come from teaching and research institutions in France or abroad, or from public or private research centers.
L'archive ouverte pluridisciplinaire HAL, est destinée au dépôt et à la diffusion de documents scientifiques de niveau recherche, publiés ou non, émanant des établissements d'enseignement et de recherche français ou étrangers, des laboratoires publics ou privés. 


\title{
LGMD: Optimal Lightweight Metadata Model for Indexing Learning Games
}

\author{
MORIE Maho Wielfrid ${ }^{1[0000-0003-0426-3046]}$, MARFISI-SCHOTTMAN Iza², GOORE Bi \\ $\mathrm{Tra}^{1}$ \\ ${ }^{1}$ Institut National Polytechnique Felix Houphouët-Boigny, 1093 Yamoussoukro, Côte d'Ivoire \\ ${ }^{2}$ Le Mans Université, EA 4023, LIUM, 72085 Le Mans, France \\ maho.moriedinphb.ci,iza.marfisieuniv-lemans.fr, \\ bitra.gooredinphb.ci
}

\begin{abstract}
Learning Games (LGs) have proven to be effective in a large variety of academic fields and for all levels; from kindergarten to professional training. They are therefore very valuable learning resources that should be shared and reused. However, the lack of catalogues that allow teachers to find existing LGs is a significant obstacle to their use in class. It is difficult for catalogues, or any type of search engine, to index LGs because they are poorly referenced. Yet, many researches have proposed elaborate metadata models for LGs. However, all these models are extensions of LOM, a metadata model that is widely used for referencing learning resources, but that contains more than 60 fields, of which more than half are irrelevant to LGs. The gap between these models and the information that game designers are willing to provide is huge. In this paper, we analyze the LG metadata models proposed in previous research to detect the fields that are specific to LGs and the fields that are irrelevant to LGs. We then propose LGMD (Learning Games Metadata Definition), an optimal lightweight metadata model that only contains the important information for LG indexing. LGMD reduces by two thirds the number of fields compared to the previous models. We confronted this model with the information actually provided by LG editors, by analyzing $736 \mathrm{LG}$ page descriptions found online. This study shows that LGMD covers all the information provided by the LG editors.
\end{abstract}

Keywords: Learning Games, LOM, Game description, Metadata Model, Learning Game Indexing, Lightweight Model.

\section{Introduction}

The use of Learning Games (LGs) has become more and more popular among teachers who want to change their teaching methods. A wide variety of LGs are developed each year for all levels of teaching. These LGs offer great potential for learning and can be used in many ways. They can be used to introduce new concepts, spice up a lab session or even as homework. Unfortunately, these learning resources are not easily accessible. The existing LG catalogues are not well adapted to the teacher's needs: either they are too specialized (only LGs for a specific field and level) or they are too 
general. Indeed, most of these catalogues offer all types of games, educational and noneducation, and are not always up to date [1-3]. Teachers who are looking for LGs therefore have to find these catalogues and browse several of them before finding the appropriate LG. Table 1 presents the three up-to-date catalogues with the most LGs, that can be found in the literature $[1,4]$.

Table 1. List of biggest Learning Games catalogues

\begin{tabular}{lrr}
\hline Catalogue & All Games & LGs \\
\hline SeriousGameClassification [5] & 3,300 & 402 \\
MobyGames [6] & 110,558 & 260 \\
Serious Games Fr [7] & 183 & 74 \\
\hline
\end{tabular}

The problem with these catalogues is that they do not offer filtering or indexing systems that facilitate the selection of LGs that are adapted to specific teaching needs. The $\mathrm{Se}$ riousGameClassification [5] catalog, for example, offers to filter the list of games depending on their purpose (e.g. educational message, subjective message, storytelling), the target market (e.g. entertainment, corporate, media), and the public (e.g. general public, 3-6 years). The MobyGames [6] catalog, on the other hand, proposes to search for games by platform (e.g. PC, Android, Nintendo), the production year (e.g. 2008, 2019), the game theme (e.g. shooter, visual novel, board game) and the rating system (e.g. PEGI rating, ESRB rating). Finally, Serious Game Fr [7] only allows searching by title and keywords. These search filters are inadequate for teachers. Not only do they not propose basic research criteria such as the educational field, the age or grade level of the students, but they do not make it easy to pick out the LGs from the non-educational games, that are much more numerous.

Yet, several elaborate LG indexing models have been proposed. These early models are based on standards established for learning resources such as the Learning Object Metadata (LOM). This standard was used for the Learning Object Repositories (LOR) project [8] and the ARIADNE project [9]. It is composed of 68 fields that cover all aspects of learning resources. In order to inventory LGs, several researchers proposed extensions of LOM by modifying the meaning of some fields and by adding extra fields to cover the gaming aspects. These metadata models are therefore very heavy, and more than half of the fields are irrelevant to LGs. Even if we consider only the appropriate fields, many appear too complex and specific for LG editors, who are simply not willing to spend time providing such detailed information [1]. In addition, LG editors do not come from the academic world and are not familiar with this standard or its vocabulary. They are more accustomed to indexing systems used in the video gaming industry.

As a result, LGs are completely absent from learning resource platforms and find themselves indexed on specialized game platforms, hidden among many non-educational games. Not only is it not very likely for teachers to find these platforms but, even if they do, the filtering systems on these platforms are of little use to find LGs that could fit their educational needs. 
In this paper, our objective is to propose an optimal metadata model for LGs, that contains only the important information to reference LGs. First, we provide an analysis of the LG metadata models proposed in previous research to detect the fields that are specific to LGs and the fields that are not relevant to LGs. We then propose LGMD (Learning Games Metadata Definition), an optimal lightweight metadata model for LGs. Finally, we test the proposed model by comparing it with the data provided by LG editors.

\section{Analysis of Metadata Models for Learning Games}

\subsection{Characterization of Learning Resources}

As any other type of learning resource, sharing and reusing LGs makes complete sense. Even more so given the fact that the development of LGs requires a lot of financial investment and a high level of skills in design, programming and scriptwriting [10, 11]. Furthermore, in the context of the constant improvement of teaching methods, the demand for these innovative pedagogical tools is high. In order to help teachers find LGs that meet their needs quickly, these resources need to be categorized with the relevant type of information [12]. Early research on LG inventories propose the use of the LOM model, widely used for describing learning resources [13, 14] and one of the key foundations to Learning Management Systems. LOM has 68 fields, organized in nine categories, that describe all aspects of learning resources $[15,16]$ :

- General - Main characteristics of the learning resource (title, description, etc.).

- Lifecycle - Information about the design of the learning resource (version, etc.).

- Meta-Metadata - Information about the metadata models used to describe the learning resource.

- Technical - Technical characteristics (format, size, installation mode, etc.).

- Educational - Pedagogical functions of the resource and its context of use (type of audience, age, language of the learner, etc.).

- Rights - Legal conditions for using the resource (costs, copyright, etc.).

- Relation - Relationships that may exist between resources.

- Annotation - Comments on the pedagogical use of the resource.

- Classification - Define the resource with classification system such as taxonomies.

LOM can be used to characterize the educational aspect of LGs, but it does not cover their gaming aspects. Important characteristics such as the platform on which the game is played (computer, console, online), the gameplay, the graphical style of the game (2D, isometric, 3D) or the type of game, are not found in LOM, initially intended for learning resources such as books, images, audio and video [11]. How can these characteristics be considered in a metadata model? In the following section we analyze several LOM extensions that aims to solve this problem. 


\subsection{Metadata Models for Learning Games}

In this section, we focus on the metadata models proposed to describe LGs. Indeed, LGs have specific characteristics that are not found in other learning resources [17] and therefore require the modification of $\operatorname{LOM}[18,19]$.

One of the first LG metadata models, proposed in 2011, is LOMFR-SG, an extension of the French version of LOM for Serious Games [20]. The authors add seven extra fields in the Educational category. Some of these are required or recommended such as "5.2 Learning Resource Type" and "5.14. Game Type" and others optional such as "5.12 resulting activity", "5.13 knowledge validation", "5.15 tutor assistance", "5.16 re-playability" and "5.17 game objectives". They also added an extra category 10. Course integration with 4 fields that provide information on how the LG can be used on the learning platform. In particular, the field " 10.4 progress indicator" indicates the information that can be used by teachers to evaluate the progress of their students (e.g. scores, gaming time, $\%$ of completion).

Another model, called G/P/S, identifies several important fields for the description of LGs [21]. For example, in the Gameplay section of this model, we can see the importance of defining the message of the game and to distinguish the student's player profile from the student's learner profile.

Hendrix et al. [22] propose to expand the existing technical category by adding information on the operating systems required to play the LGs, in addition to the platform (i.e. PC, Nintendo, Tablet, etc.). They also add a field related the game's scoring based on systems such as the PEGI (Pan European Game Information) [22, 23].

Similarly, the contributions of the SG-LOM model [24] add several fields: "8.5 game rating", "8.4 gaming experience required" and "5.18 multiplayer value". They also add the recommended field "9.5 gameplay" which provides information about the graphical style of the LG (e.g. 2D, isometric, 3D).

Table 2 combines the above proposals, in which we find 60 fields (20 required or recommended and 40 optional). Most of the additions (marked with a *) or modifications are in the Educational categories and in the new category 10 Course integration.

Table 2. LOM field extensions to match the characteristics of Learning Games

\begin{tabular}{|c|c|c|c|}
\hline Categories & Main Fields & Quality & Authors \\
\hline \multirow{9}{*}{ 1. General } & 1.1 Identifier & Req & \\
\hline & 1.2 Title & Req & \\
\hline & 1.3 Language & $\operatorname{Rec}$ & \\
\hline & 1.4 Description & $\operatorname{Rec}$ & \\
\hline & 1.5 Keywords & $\operatorname{Rec}$ & \\
\hline & 1.6 Coverage & Opt & \\
\hline & 1.7 Structure & Opt & \\
\hline & 1.8 Aggregation Level & Opt & \\
\hline & 1.9 Documentary Type* & $\operatorname{Rec}$ & LOMFR-SG \\
\hline \multirow{4}{*}{ 2. Lifecycle } & 2.1 Version & Rec & \\
\hline & 2.2 Status & Rec & \\
\hline & 2.3 Contribution & Rec & \\
\hline & 3.1 Identifier & Opt & \\
\hline
\end{tabular}




\begin{tabular}{|c|c|c|c|}
\hline $\begin{array}{l}\text { 3. Meta- } \\
\text { Metadata }\end{array}$ & $\begin{array}{l}\text { 3.2 Contribution } \\
\text { 3.3 Metadata Schema } \\
\text { 3.4 Language }\end{array}$ & $\begin{array}{l}\text { Opt } \\
\text { Opt } \\
\text { Opt }\end{array}$ & \\
\hline \multirow{7}{*}{ 4. Technical } & 4.1 Format & $\operatorname{Rec}$ & LOMFR-SG \\
\hline & 4.2 Size & Opt & \\
\hline & 4.3 Location & $\operatorname{Rec}$ & LOMFR-SG \\
\hline & 4.4 Platform Requirements* & Opt & LOMFR-SG, SG-LOM \\
\hline & 4.5 Installation Remarks & Opt & \\
\hline & 4.6 Other Platform Requirements & Opt & \\
\hline & 4.7 Duration & Opt & \\
\hline \multirow{18}{*}{ 5. Educational } & 5.1 Interactivity Type & Opt & \\
\hline & 5.2 Learning Resource Type* & $\operatorname{Rec}$ & LOMFR-SG \\
\hline & 5.3 Interaction Level & Opt & \\
\hline & 5.4 Semantic Density & Opt & \\
\hline & 5.5 Public & $\operatorname{Rec}$ & \\
\hline & 5.6 Context & $\operatorname{Rec}$ & \\
\hline & 5.7 Typical Age Range & Opt & \\
\hline & 5.8 Difficulty & Opt & \\
\hline & 5.9 Typical Learning Time & Opt & \\
\hline & 5.10 Description & Opt & \\
\hline & 5.11 Language & Opt & \\
\hline & 5.12 Resulting Activity* & Opt & LOMFR-SG \\
\hline & 5.13 Knowledge validation* & Opt & LOMFR-SG \\
\hline & 5.14 Game Type* & $\operatorname{Rec}$ & LOMFR-SG \\
\hline & 5.15 Tutors assistance* & Opt & LOMFR-SG \\
\hline & 5.16 Re-Playability* & Opt & LOMFR-SG, SG-LOM \\
\hline & 5.17 Game objectives* & Opt & LOMFR-SG \\
\hline & 5.18 Multiplayer Value* & Opt & SG-LOM \\
\hline \multirow{3}{*}{ 6. Rights } & 6.1 Cost & Opt & \\
\hline & 6.2 Copyright & $\operatorname{Rec}$ & \\
\hline & 6.3 Description & $\operatorname{Rec}$ & \\
\hline \multirow{2}{*}{ 7. Relation } & 7.1 Kind of relation & Opt & \\
\hline & 7.2 Resource & Opt & \\
\hline \multirow{5}{*}{ 8. Annotation } & 8.1 Entity & Opt & \\
\hline & 8.2 Date & Opt & \\
\hline & 8.3 Description & Opt & \\
\hline & 8.4 Gaming Experience Required* & Opt & SG-LOM, [20], [24] \\
\hline & 8.5 Game Rating* & Opt & SG-LOM, [22] \\
\hline \multirow{5}{*}{ 9. Classification } & 9.1 Purpose & $\operatorname{Rec}$ & SG-LOM, G/P/S, [22] \\
\hline & 9.2 Taxon Path & Opt & \\
\hline & 9.3 Description & Opt & \\
\hline & 9.4 Keywords & Opt & \\
\hline & 9.5 Gameplay* & $\operatorname{Rec}$ & SG-LOM ,G/P/S \\
\hline \multirow{4}{*}{$\begin{array}{l}\text { 10. Course In- } \\
\text { tegration* }\end{array}$} & 10.1 Component Type* & $\operatorname{Rec}$ & LOMFR-SG \\
\hline & 10.2 Available settings* & Opt & LOMFR-SG \\
\hline & 10.3 Observables* & Opt & LOMFR-SG \\
\hline & 10.4 Progress indicators* & Opt & LOMFR-SG , SG-LOM, [22] \\
\hline
\end{tabular}

* Categories and field added in LOM extension

Req=Required, $\mathrm{Rec}=$ Recommended, Opt=Optional 
There are several similarities between the model proposals that show the importance of the added fields. Apart from LOMFR-SG, which removes three fields from the Educational category, the other metadata schemas keep all the LOM fields, probably to stay compatible with existing learning resource repositories. However, in reality, only 20 fields are actually used in most of the learning repositories [25]. The authors of this study also estimate that the LOM fields are not used correctly in $68 \%$ of the cases. Furthermore, it is very rare to find learning repositories that simultaneously reference textual documents, audiovisual materials and LGs. Is it therefore relevant to keep so many fields that will certainly not be used?

It is difficult for the LG editors and catalogue designers to reference LGs according to metadata models with so many fields and several ambiguities [20]. For example, the field "language", which is found in several categories (General, Pedagogical and Metadata) with different values for each of them, can create confusion in its interpretation. The same applies to the fields "description", "contribution" and "platform requirements". Therefore, we may wonder whether the proposed LOM extensions do not add more weight to the already complex metadata schema? We therefore propose, in the following section, a lightweight metadata model, that will contain only the fields that are relevant to $\mathrm{LG}$ characteristics.

\section{$3 \quad$ Learning Game Metadata Definition (LGMD)}

\subsection{LGMD description}

The analysis of LG metadata models shows that previous research has resulted in extensions that make LOM even more complex. The challenge is to propose an optimal metadata model, that contains only the fields necessary for describing LGs in all their complexity. Our hypothesis is that this optimal model can be found by keeping all the fields that were identified as important in the previous LG metadata models and removing all the fields that are not relevant to LGs.

\section{General Category}

. In this category, we keep all the fields with the quality "required" or "recommended" (see Table 3). We also remove the field "document type", since all the LGs would have the same value "Learning Game" for this field. We also remove the field "1.1 identifier" because this information is provided by the catalog rather than the LG editors.

Table 3. Fields in the General category of the LGMD model

\begin{tabular}{lll}
\hline Fields & Explanation & Quality \\
\hline Title & Title or name of the LG & Req \\
Language & LG language & Rec \\
Description & Complete description of the LG and its environment & Req \\
Keywords & Set of keywords to classify the LG without reading the description & Req \\
\hline
\end{tabular}




\section{Lifecycle Category}

. In this category, we remove the field "status" which deals with the availability of the LG, because we do not find useful to index unavailable LGs and this information can be found in the "version" field. In addition, we add the field "date" to describe the date of LGs release.

\section{Technical Category}

. In addition to the fields qualified as recommended, we keep the fields "size" and "technical requirement" which describe respectively the size and the platform required to run the LG. We believe the last field is essential because it will help teachers select LGs according to the material, they have access to (e.g. tablet, computer, Nintendo).

\section{Educational Category}

. In this category, we merge the fields "context" and "public" since they describe the same information. We remove the "learning resource type" that would be "application/game" for all LGs. We add the field "domain", which is originally part of values of field "9.1 purpose" in the Classification category. It seems important to include this field in the Educational Category because it describes the educational field for with the LG can be used. Finally, we keep the field "progress indicator", that was in the extra category (10 - Course integration), added by the LG metadata models (see Table 4).

Table 4. Fields in the Educational category of the LGMD model

\begin{tabular}{|c|c|c|c|}
\hline Fields & Meaning & Examples & Quality \\
\hline Public & $\begin{array}{l}\text { The type of learner for } \\
\text { whom the LG is intended }\end{array}$ & Student, Middle-School & $\operatorname{Rec}$ \\
\hline Age Range & $\begin{array}{l}\text { The age required for using } \\
\text { the } L G\end{array}$ & $6-10^{\text {th }}, 18+,-6$ & $\operatorname{Rec}$ \\
\hline Game Type & The type of gameplay & $\begin{array}{l}\text { Puzzle, Strategy, Adven- } \\
\text { ture }\end{array}$ & $\operatorname{Rec}$ \\
\hline Domain & $\begin{array}{l}\text { The field of study for which } \\
\text { the LG can be used }\end{array}$ & $\begin{array}{l}\text { Math, Biology, Environ- } \\
\text { ment }\end{array}$ & Req \\
\hline Resulting Activity & $\begin{array}{l}\text { The pedagogical activities } \\
\text { engaged during the LG }\end{array}$ & $\begin{array}{l}\text { Create, exchange, Organ- } \\
\text { ize }\end{array}$ & Opt \\
\hline $\begin{array}{l}\text { Knowledge Vali- } \\
\text { dation }\end{array}$ & $\begin{array}{l}\text { The skills and knowledge } \\
\text { developed with the LG }\end{array}$ & $\begin{array}{l}\text { The alphabet, quantum } \\
\text { physics, ecofriendly atti- } \\
\text { tude }\end{array}$ & Opt \\
\hline Multiplayer value & The game mode & Solo, Multiplayer & Opt \\
\hline $\begin{array}{l}\text { Progress Indica- } \\
\text { tor }\end{array}$ & $\begin{array}{l}\text { Information on the learn- } \\
\text { er's progression in the LG }\end{array}$ & $\begin{array}{l}\text { Scoring, percentage of } \\
\text { good answers, timer }\end{array}$ & Opt \\
\hline
\end{tabular}

\section{Rights Category}

. The "description" field of this category creates an ambiguity with those in the General and Annotation categories and the information can be provided in the "copyright" field value. Thus, only the "copyright" and "cost" fields are kept. 


\section{Category Classification}

. In this category, we integrate the field "game rating" proposed by the LOM extensions in the category "Annotation", since we consider it is a characteristic of the LG that allows us to classify it. Indeed, the rating systems used as values in this field are considered as classification systems based on the player's profile (e.g. PEGI +3, ESRB +14) $[26,27]$. We also keep the field "gameplay" proposed by the LOM extensions. We remove the other fields because they are redundant. Indeed, the "taxon path" field that describes the taxonomy in which the LG is classified represents a different classification model that needs to be dissociated from the metadata model. The same applies to the "description" and its associated "descriptor" fields. The "9.1 purpose" field is in fact a collection of values that can be found in several other fields such as "8.4 gaming experience required", "5.13 knowledge validation" and "5.5 public". Often, in this field, we find a value about the domain of LGs. Yet, this is the essential educational information we need to have about LGs.

\subsection{LGMD model overview}

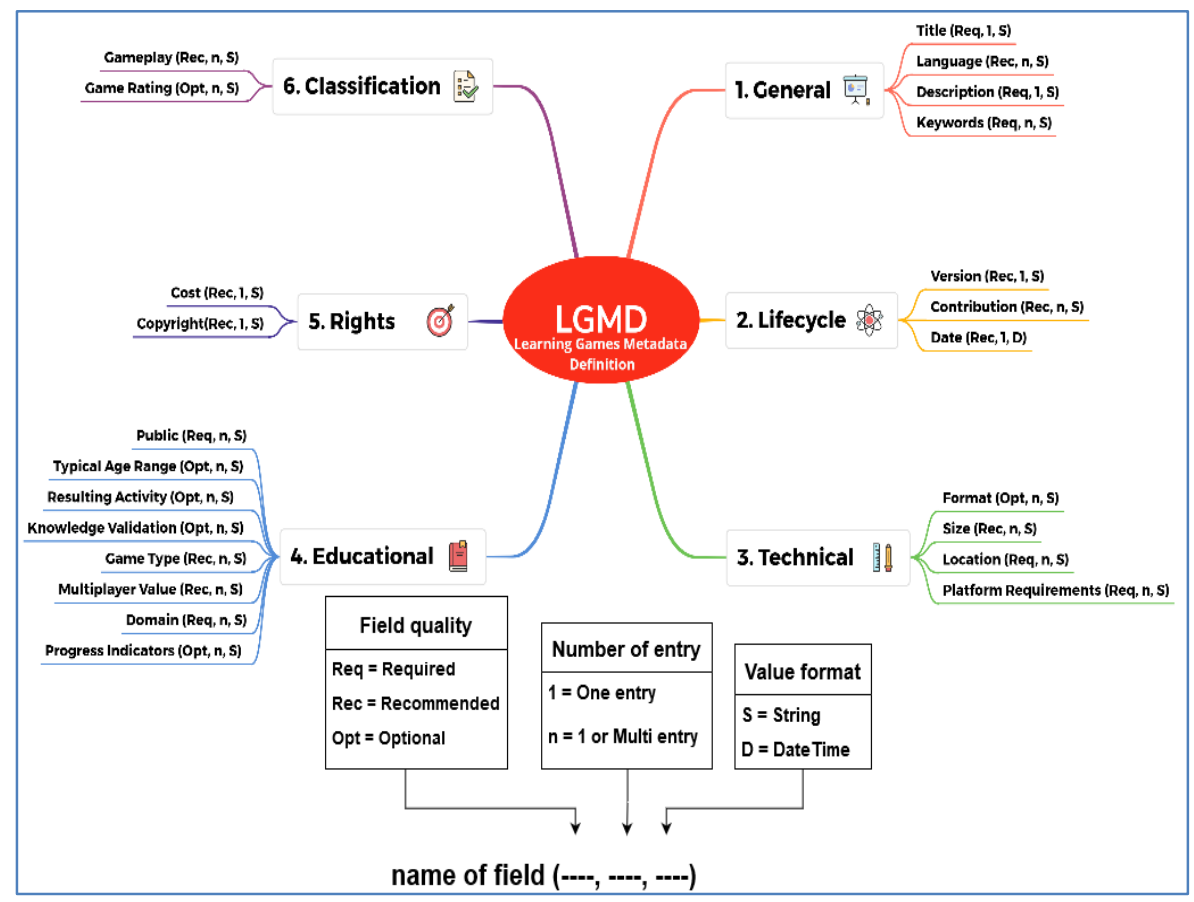

Fig. 1. Overview of the Learning Game Metadata Definition fields

In summary, the LGMD model keeps most of the fields qualified as required or recommended and deletes the fields qualified as optional, except for some that we consider important for the description of LGs such as the fields "5.12 resulting activity" and 
"5.13 knowledge validation", "4.2 size" and "4.4 Platform requirements". The categories Meta-metadata, Relation and Annotation are removed because they do not provide significantly useful information for the description of LGs and result in creating ambiguity.

As depicted in figure 1, the resulting LGMD model has 23 fields, divided into six categories. It reduces the fields of the metadata models studied previously by two thirds, as it is intended to be concise and simple so that it can be easily used by LG editors. However, the trap to be avoided is removing too many fields. Removing fields that could be relevant for describing LGs. In the next section, we therefore verify if the LGMD metadata model covers all the information currently provided by LG editors.

\section{$4 \quad$ Analysis of Data Provided by Learning Games Editors}

\subsection{Data Collection}

The LGMD model is designed to be lighter and easier to use for LG editors than the existing models based on LOM extensions [20, 25]. We therefore removed all the fields that seemed redundant or irrelevant to LGs. In order to make sure we did not remove too many fields, we need to ensure that the fields in LGMD still cover the information actually provided by LG editors.

To do this, we analyze data from 736 LGs, available in the three major LG catalogues (see Table 1). We limited ourselves to LGs created after 2008 and available on the main platforms (PC, Mac, Smartphone, Tablet) and operating systems (Windows, Linux, iOS, Android) or online.

As LG editors do not follow a specific metadata model, we used the description information of their LGs to find the values for each of the fields of the LOM extension models presented in table 2 and the fields of the proposed LGMD model. We rely on an automatic extraction model, presented in previous work, that parses and analyzes text on web pages. This extraction model was tested on a sample of $24 \mathrm{LG}$ web pages, with the help of teachers. Even though these pages had very different formats (e.g. simple pages, pages with popups, pages presenting several LGs), the keywords extracted for each of the metadata fields have an average accuracy score of $80 \%$ with a minimum of $60 \%$. The extraction of the text for the "description" field is particularly good with an average accuracy level of $85 \%$, and never lower than $80 \%$. This extraction model can therefore be considered as an effective way to extract useful information for each metadata field.

\subsection{Result Analysis}

The analysis of the data from the 736 LGs shows that only the information for 17 fields is provided (out of the 23 in the LGMD model and the 70 in the LOM extension).

First of all, it is important to note that the extraction model found absolutely no information for the 47 fields, that were in the LOM extensions, and that we considered non-relevant. 


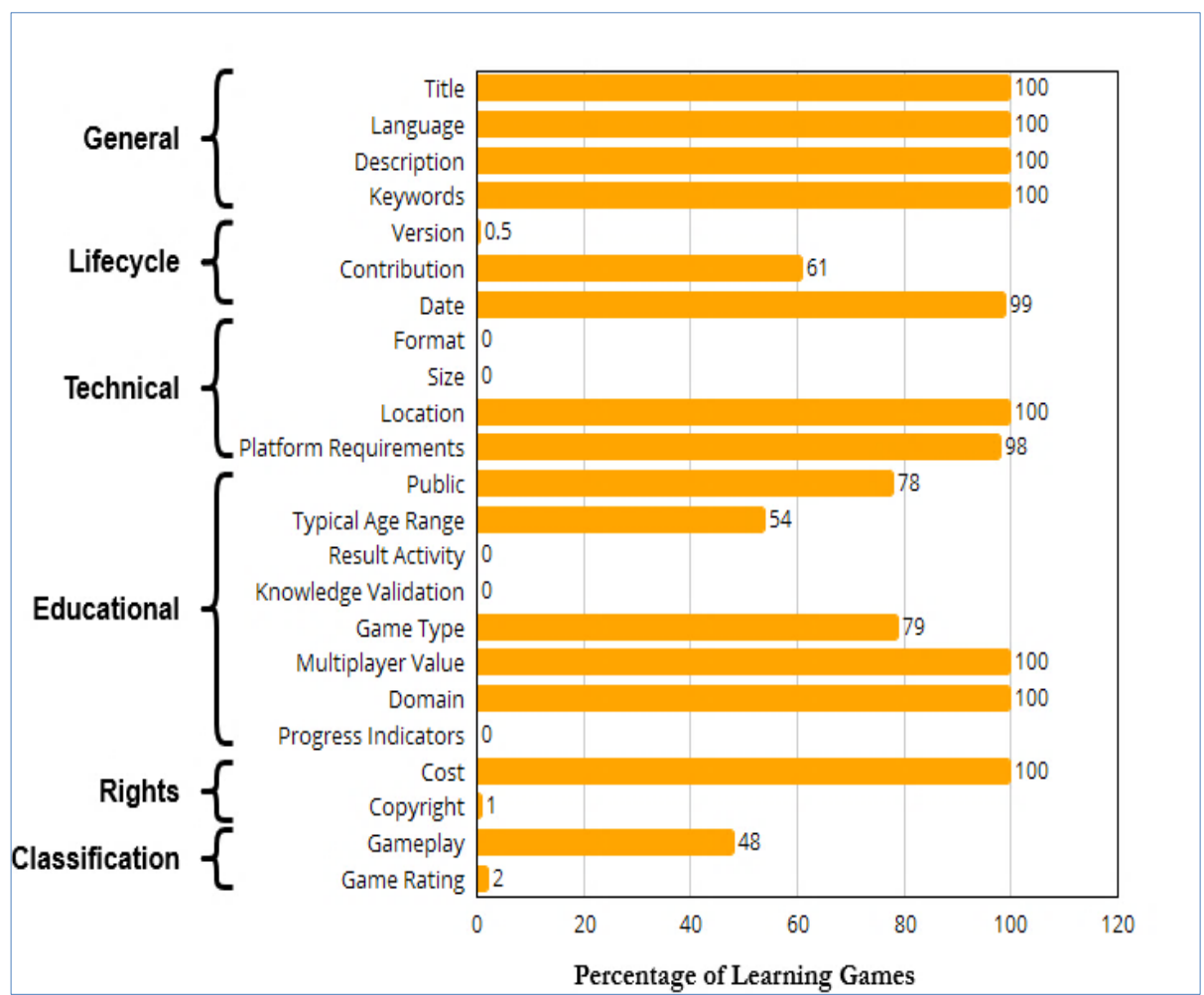

Fig. 2. Percentage of Data Provided by LG developers

As depicted in Figure 2, out of the 23 fields in LGMD, 10 fields are provided 100\% of the time and five fields are provided about $50 \%$ of the time. However, it appears to be very hard to find information for the remaining fields. The information for the "copyright" field is only found on $1 \%$ of the pages, $2 \%$ for the "game rating" and $0.5 \%$ for the "version". For the remaining 5 fields of the LGMD (i.e. "format", "size", "result activity", "knowledge validation" and "progress indicators") none of the LG editors of the 736 LGs provide this information (0\%). Nonetheless, all fields marked as required or recommended in LGMD are represented at least once. The statistics also show that the completion rate of all the categories in LGMD is at least $50 \%$. For the General, Rights and Classification categories this number goes up to $100 \%$ (see Fig. 3).

For the LOM extensions, on the other hand, the completion rate for the categories are much lower. The Meta-Metadata, Relation and Annotation categories have absolutely no fields provided so we did not represent then on the figure 3. Only the Rights category has more than $50 \%$ of its fields filed out. The data provided for the other categories (e.g. General, Lifecycle, Technical, Educational and Classification) is between $20 \%$ and $44 \%$. 


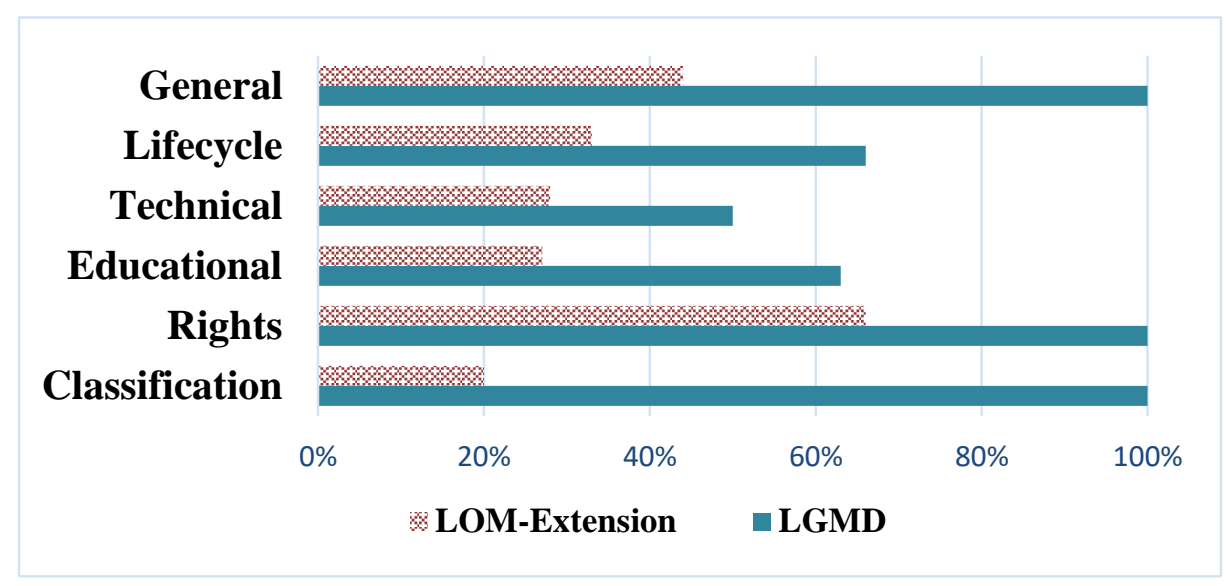

Fig. 3. Percentage of data provided per category in LOM extensions compared to LGMD.

\subsection{Discussion}

The first interpretation we can make of these results is that the LGMD model covers all the information provided by LG editors, despite the reduced number of its fields. The fact that LG editors do not provide any information for the fields that were not selected for LGMD proves they are not relevant for LGs.

However, the information for some of the fields in LGMD is also very close or equal to $0 \%$. For example, the information regarding the version of the LG is very rarely provided by LG editors. This can be explained by the fact that they probably always provide the latest version of their LGs. However, it is essential that editors provide this information that can guide teachers in their choice of LGs. A new version of a LG may target newer material and teachers may be looking for an earlier game release for older material. Alternatively, a teacher may be looking for a particular version in which emphasis was put on a particular part of a lesson.

Similarly, none of the LG editors provide information for the field "knowledge validation" which could be very useful for teachers. Indeed, the text description written by LG editors only provide information on the educational field without giving a list of the precise target knowledge that one can acquire with the LG. This is probably due to the fact that LG editors are not acquainted with the precise terms used in academia to describe. This can also explain why no information can be found for the field "resulting activity".

Even though very little information can be found on LGs pages for these fields in the current catalogues, we argue that they should be kept in order to encourage LG editors to provide this information that will no doubt help teachers find the appropriate LGs.

Regarding the fields provided at a low percentage such as "game rating", we can observe that for all the LGs where the "typical age range" is provided (e.g. 3 to 6 years old), the "game rating" (e.g. PEGI +3 which means for kids three years and up, ESRB 
-14 which means for kids younger than 14) is not provided and vice versa (Figure 4). We explain this phenomenon by the fact that these two fields provide similar types of information on the age of the learners with the "public" field. Perhaps a field that can group the data types of these three fields together would allow for a more concise metadata schema.

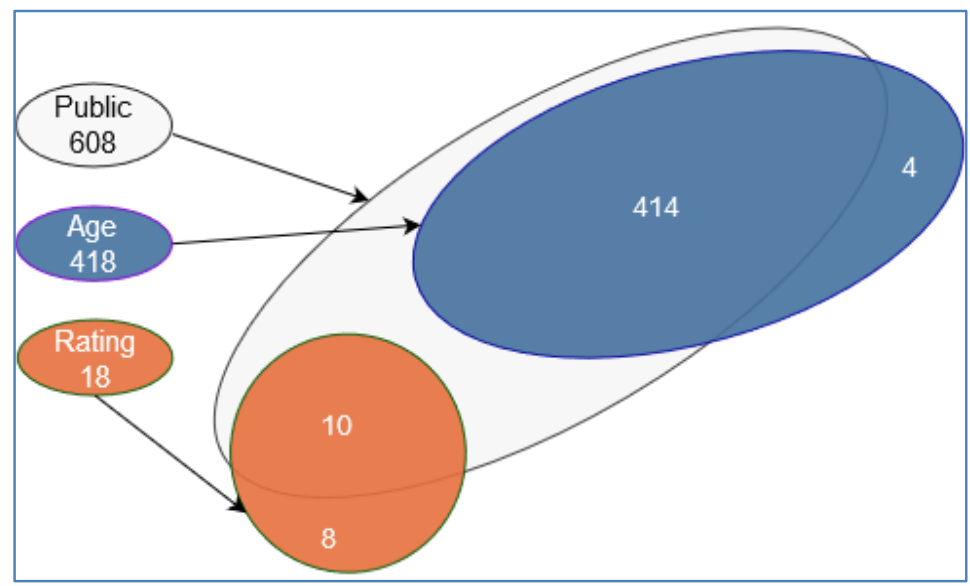

Fig. 4. Distribution of the age and assessment fields in relation to the public field

\section{Conclusion}

Many Learning Games (LGs) have been created these past years but there is still no centralized platform that allows teachers to search for existing LGs and find those that meet their specific teaching needs. Several researchers have tried to reproduce the success of Learning Object Repositories that are widely used in academia. Several extensions of the Learning Object Metadata (LOM) standard have been proposed. However, these extensions, based on an already heavy model, offer more than 70 fields and use very specific and complex vocabulary. LG editors are not familiar with these standards and are simply not willing to spend so much time providing information for all these fields, including the fact that more than half of the fields are irrelevant for LGs.

In this paper, we propose LGMD (Learning Games Metadata Definition), a lightweight optimal LG metadata model with only 23 fields distributed in 6 categories: general, lifecycle, technical, educational, rights and classification. It contains only the fields of the LOM extensions that are relevant for LGs. Despite its limited number of fields, an analysis of $736 \mathrm{LG}$ web pages, proves that it covers all the data currently provided by LG editors. The information for $2 / 3$ of these fields can be found in more than $50 \%$ of the cases. We argue that the remaining eight fields, for with editors rarely provide information, should be kept, in order to encourage them to provide this information, which will help teachers find their ideal LG. In addition, LGMD is retro com- 
patible with the LOM standard. This means that the referencing of an educational resource with the LGMD can be converted into LOM. This compatibility ensures the interoperability with existing learning resource repositories.

The proposed LGMD model is therefore suitable for practical use by editors in the referencing of their LGs. However, further studies are needed to measure how practical LGMD is for the LGs indexing. Moreover, we intent to use this model to reference LGs in a new catalogue. The filtering tools and the vocabulary used will need to be validated with the participation of teachers of all levels and from various disciplines.

\section{References}

1. Alvarez, J., Plantec, J.-Y., Vermeulen, M., Kolski, C.: RDU Model dedicated to evaluate needed counsels for Serious Game projects. Computers \& Education. 114, 38-56 (2017). https://doi.org/10.1016/j.compedu.2017.06.007.

2. Fronton, K., Vermeulen, M., Quelennec, K.: LES ECSPER : RETOUR D'EXPERIENCE D'UNE ETUDE DE CAS DE TYPE SERIOUS GAME EN GESTION DE PROJET. Presented at the e-Formation des adultes et des jeunes adultes June 3 (2015).

3. Mitamura, T., Suzuki, Y., Oohori, T.: Serious games for learning programming languages. In: 2012 IEEE International Conference on Systems, Man, and Cybernetics (SMC). pp. 1812-1817 (2012). https://doi.org/10.1109/ICSMC.2012.6378001.

4. Gottron, T.: Combining Content Extraction Heuristics: The CombinE System. In: Proceedings of the 10th International Conference on Information Integration and Web-based Applications \& Services. pp. 591-595. ACM, New York, NY, USA (2008). https://doi.org/10.1145/1497308.1497418.

5. Serious Game Classification: La classification en ligne du Serious Game, http://serious.gameclassification.com/, last accessed 2020/01/13.

6. MobyGames: Game Browser, https://www.mobygames.com/browse/games, last accessed 2020/01/13.

7. La référence Serious Games, https://www.serious-game.fr/, last accessed 2020/01/13.

8. Neven, F., Duval, E.: Reusable Learning Objects: A Survey of LOM-based Repositories. In: Proceedings of the Tenth ACM International Conference on Multimedia. pp. 291-294. ACM, New York, NY, USA (2002). https://doi.org/10.1145/641007.641067.

9. Currier, S.: Metadata for Learning Resources: An Update on Standards Activity for 2008. Ariadne. (2008).

10. Alvarez, J.: Du jeu vidéo au serious game, (2007).

11. Michael Zyda: From Visual Simulation to Virtual Reality to Games. Computer. 38, 25-32 (2005). https://doi.org/10.1109/MC.2005.297.

12. Wirth, C., Fürnkranz, J.: On Learning From Game Annotations. IEEE Transactions on Computational Intelligence and AI in Games. 7, 304-316 (2015). https://doi.org/10.1109/TCIAIG.2014.2332442.

13. Massart, D., Shulman, E.: Learning Resource Exchange Metadata Application Profile Version 4.7. 127 (2011). 
14. Rajabi, E., Sicilia, M.-A., Sanchez-Alonso, S.: Interlinking educational resources to Web of Data through IEEE LOM. Computer Science and Information Systems. 12, 233-255 (2015). https://doi.org/10.2298/CSIS140330088R.

15. McClelland, M.: Metadata standards for educational resources. Computer. 36, 107-109 (2003). https://doi.org/10.1109/MC.2003.1244540.

16. Pernin, J.-P.: LOM, SCORM et IMS-Learning Design: ressources, activités et scénarios. In: actes du colloque «L'indexation des ressources pédagogiques numériques», Lyon (2004).

17. Aouadi, N., Pernelle, P., Marty, J.-C., Carron, T.: A model driven architecture MDA approach to facilitate the serious game integration in an e-learning environment. In: European Conference on Games Based Learning. p. 15. Academic Conferences International Limited (2015).

18. Prensky, M.: Digital Game-based Learning. Comput. Entertain. 1, 21-21 (2003). https://doi.org/10.1145/950566.950596.

19. Freire, M., Fernández-Manjón, B.: Metadata for Serious Games in Learning Object Repositories. IEEE Revista Iberoamericana de Tecnologias del Aprendizaje. 11, 95-100 (2016). https://doi.org/10.1109/RITA.2016.2554019.

20. Marfisi-Schottman, I., George, S., Tarpin-Bernard, F.: Un profil d'application de LOM pour les Serious Games. In: Environnements Informatiques pour l'Apprentissage Humain, Conférence EIAH'2011. pp. 81-94. Editions de 1'UMONS, Mons 2011, Belgium (2011).

21. Djaouti, D., Alvarez, J., Jessel, J.-P.: Classifying Serious Games: the G/P/S model. Handbook of Research on Improving Learning and Motivation through Educational Games: Multidisciplinary Approaches. (2011). https://doi.org/10.4018/978-1-60960-495-0.ch006.

22. Hendrix, M., Protopsaltis, A., de Freitas, S., Arnab, S., Petridis, P., Rolland, C.: Defining a Metadata Schema for Serious Games as Learning Objects. 6 (2012).

23. Dogruel, L., Joeckel, S.: Video game rating systems in the US and Europe: Comparing their outcomes. International Communication Gazette. 75, 672-692 (2013).

24. Elborji, Y., Khaldi, M.: An IEEE LOM Application Profile to Describe Serious Games «SG-LOM». IJCA. 86, 1-8 (2014). https://doi.org/10.5120/15042-3404.

25. Ochoa, X., Klerkx, J., Vandeputte, B., Duval, E.: On the Use of Learning Object Metadata: The GLOBE Experience. In: Kloos, C.D., Gillet, D., Crespo García, R.M., Wild, F., and Wolpers, M. (eds.) Towards Ubiquitous Learning. pp. 271-284. Springer Berlin Heidelberg (2011).

26. Konzack, L.: Pan European Game Information (PEGI) system. Encyclopedia of video games: The culture, technology, and art of gaming. 2, 474-476 (2012).

27. Bushman, B.J., Cantor, J.: Media ratings for violence and sex: Implications for policymakers and parents. American Psychologist. 58, 130-141 (2003). https://doi.org/10.1037/0003066X.58.2.130.

28. Klopfer, E., Sheldon, J., Perry, J., Chen, V.: Ubiquitous games for learning (UbiqGames): Weatherlings, a worked example. Journal of Computer Assisted Learning. 28, (2012). https://doi.org/10.1111/j.1365-2729.2011.00456.x.

29. Adams, E.: Fundamentals of Game Design. New Riders Publishing, Thousand Oaks, CA, USA (2014). 